\title{
PEMODELAN KONTROL SUHU, TEKANAN, DAN LAJU ALIRAN UAP PADA KONDENSOR DENGAN MENGGUNAKAN KONTROL LOGIKA FUZZY
}

\author{
Alviano Markus Sigarlaki ${ }^{1)}$, Hesky Stevy Kolibu ${ }^{1)}$, Verna Albert Suoth ${ }^{1)}$ \\ ${ }^{1)}$ Program Studi Fisika, FMIPA UNSRAT \\ e-mail: alkavingaul@yahoo.co.id, heskystevy@yahoo.com, vernasuoth@yahoo.co.id
}

\begin{abstract}
ABSTRAK
Kondensor adalah komponen pendingin yang digunakan dalam sistem PLTP Lahendong untuk mengubah uap menjadi air. Banyak hal yang terjadi pada kondensor seperti kevakuman tekanan kondensor yang sering naik turun, serta laju aliran uap dari turbin yang tidak stabil. Hal ini dapat mempengaruhi efisiensi kerja kondensor. Pemodelan kontrol suhu, tekanan dan laju aliran uap pada kondensor dengan menggunakan kontrol logika fuzzy, dilakukan untuk memperoleh efisiensi yang baik pada proses kerja kondensor. Penelitian ini menggunakan data sekunder dari PLTP Lahendong yang diolah dan dianalisis dengan software logika fuzzy menurut aturan rule yang ditentukan. Hasil dan analisis tersebut dipakai untuk melihat keefektifan hubungan antara input dan output. Hasil pengontrolan fuzzy dapat menunjukkan stabilitas dan keefektifan yang terjamin. Hal ini terlihat pada volume air kondensor yang cenderung stabil dengan nilai error pada RMSE adalah 0.7847 .
\end{abstract}

Kata kunci : Model Logika Fuzzy, Kondensor, Kontrol Logika Fuzzy

\section{DESIGN TEMPERATURE CONTROL PRESSURE STEAM FLOW RATE IN THE CONDENSER USED FUZZY LOGIC CONTROL}

\begin{abstract}
Condenser is cooling components used in the system PLTP Lahendong to change steam into water. Many things that happen in the condenser such as vacuum condenser pressure is often up and down, also the flow rate of the steam turbine unstable. This can affect the efficiency of the condenser. Design control temperature, pressure and flow rate of steam in the condenser by using fuzzy logic control, performed to obtain a good efficiency in the work process condenser. This study uses secondary data from PLTP Lahendong processed and analyzed with fuzzy logic software according to the rules specified rule. Results and analysis are used to see the effectiveness of the relationship between inputs and outputs. The results of fuzzy control can demonstrate the stability and effectiveness are guaranteed. This can be seen in the volume of water condenser with a stable trend in the RMSE error value is 0.7847 .
\end{abstract}

Keywords : Design Fuzzy Logic, Condenser, Control Fuzzy Logic

\section{PENDAHULUAN}

Perkembangan teknologi informasi yang terjadi saat ini begitu cepat, terlihat pada penggunaan teknologi komputer dan telekomunikasi yang semakin bertambah. Perubahan yang terjadi pada komputer baik pada perangkat keras (hardware) dan perangkat lunak (software) memaksa pengguna untuk mengikuti perubahan teknologi yang ada (William, 1991).
Matlab menyediakan beberapa fasilitas untuk menganalisis data. Salah satu fasilitas yang digunakan dalam penelitian ini adalah fuzzy logic toolbox. Logika fuzzy didefinisikan sebagai suatu metode yang di pakai untuk memetakan suatu ruang masukan kedalam suatu ruang keluaran. Dalam penelitian ini, fungsi dari logika fuzzy adalah sebagai pengontrol, yang digunakan pada kondensor untuk memodelkan tekanan, suhu, dan laju ailran uap pada kondensor. 
Kondensor yang digunakan dalam penelitian ini adalah kondensor PLTP Lahendong unit 1. Uap yang digunakan untuk memutar turbin adalah uap dari panas bumi yang dapat mencemari lingkungan karena masih terdapat banyak gas-gas berbahaya seperti $\mathrm{H}_{2} \mathrm{~S}$ dan lain sebagainya. Uap yang dipakai setelah pemutaran pada turbin dikondensasi menjadi air oleh kondensor dan diinjeksikan kembali ke bumi agar tidak mencemari lingkungan.

Kondensor ini dipakai sebagai alat perpindahan panas yang dilepaskan dari uap panas refrigeran ke media pendingin sehingga uap panas refrigeran akan mengalami pengembunan dan perubahan fase dari keadaan uap menjadi cairan. Banyak hal yang terjadi pada kondensor, misalnya kebocoran pada tabung, kevakuman pada kondensor yang tidak konstan atau sering naik turun, terjadinya penyumbatan pada tabung kondensor yang dapat menurunkan kinerja sistem pada kondensor dalam mentransfer panas sehingga keefektifannya menjadi berkurang (Kusmadewi, et all. 2012).

Prinsip kerja dari kondensor adalah untuk mencapai suhu kondensasi yang rendah. Untuk memperoleh suhu kondensasi yang rendah, maka uap yang masuk dalam kondensor di dinginkan dengan air. Menurut (Dossat, 1961) suhu yang sangat tinggi dan laju aliran massa yang rendah pada media pendingin saat kondensor beroperasi, akan menyebabkan suhu kondensasi tidak maksimal. Jika tekanan dalam kondensor terlalu berlebihan maka akan menyebabkan laju aliran uap yang masuk pada kondensor menurun

Tekanan pada kondensor harus tetap dijaga kevakumannya agar uap yang dipakai untuk memutar turbin dapat masuk pada kondensor serta putaran turbin pun dapat maksimal. Jika suhu pada kondensor terlalu berlebihan, maka akan mempengaruhi tekanan pada kondensor. Uap yang telah dikondensasikan menjadi air ditampung pada tabung kondensor. Jika air hasil kondensasi memenuhi tabung kondensor maka akan menyebabkan kerja dari kondensor tidak berjalan dengan baik. Laju aliran uap yang masuk pada kondensor perlu dikontrol agar air hasil kondensasi tidak memenuhi tabung kondensor.

Berdasarkan dari uraian tersebut maka perlu untuk memodelkan suhu, tekanan, dan laju aliran pada kondensor agar dapat bekerja dengan maksimal.

\section{Rumusan Masalah}

Bagaimana memodelkan suhu, tekanan dan laju aliran uap dalam memaksimalkan proses kerja kondensor dengan kontrol logika fuzzy?

\section{Batasan Masalah}

Penelitian ini dibatasi pada pemodelan pengontrolan suhu, tekanan dan laju aliran uap pada kondensor dengan pengontrol logika fuzzy dalam matlab.

\section{Tujuan Penelitian}

Penelitian ini bertujuan untuk memodelkan suhu, tekanan dan laju aliran uap dalam memaksimalkan kerja kondensor

\section{TINJAUAN PUSTAKA}

Suhu

Suhu merupakan ukuran atau derajat panas dinginnya suatu benda atau sistem (ukuran energi kinetik rata-rata yang dimiliki oleh molekul-molekul suatu benda).. Suhu merupakan salah satu dari ketujuh besaran pokok sistem internasional (SI). Suhu absolute (T) adalah derajat diatas suhu nol absolute yang dinyatakan dengan dengan Kelvin : (K) ; yaitu $\mathrm{T}=\mathrm{t}^{\circ} \mathrm{C}+273$ (Halliday Resnick, 1994).

\section{Tekanan}

Tekanan adalah gaya normal (tegak lurus) yang diberikan oleh suatu fluida persatuan luas benda yang terkena gaya tersebut atau dituliskan :

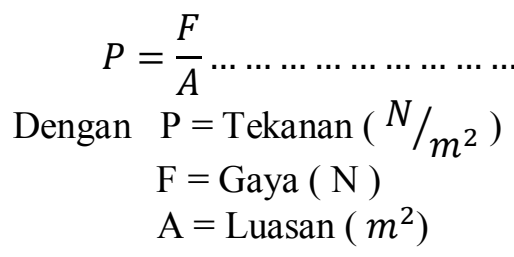

\section{Laju Aliran}

Laju aliran didefinisikan sebagai banyaknya zat yang mengalir dengan kecepatan tertentu persatuan waktu atau $\mathrm{kg} /$ detik. Pernyataan yang sering digunakan untuk laju aliran massa yaitu $d m / d t$ atau biasanya dituliskan $\dot{m}$, melalui sebuah bagian dari permukaan dengan luas A adalah

$$
\dot{m}=\rho A \vartheta \text {. }
$$


di mana $\rho$ adalah kerapatan fluida, $\vartheta$ adalah komponen kecepatan fluida yang tegak lurus bidang A.

\section{Beberapa Hukum Tentang Gas}

Setiap sistem dengan massa tetap yang melakukan tekanan hidrostatik serba sama pada lingkungannya, tanpa efek permukaan, gravitasi, listrik, dan magnetic disebut sistem hidrostatik. Sistem hidrostatik dibagi dalam kategori sebagai berikut :

1. Zat murni, yaitu zat yang hanya terdiri atas satu bahan kimia yang berbentuk padat, cair, gas atau campuran dari dua atau tiga bentuk itu

2. Campuran serba sama dari bahan yang berbeda, seperti campuran gas lemban, campuran gas aktif kimiawi, campuran cairan atau larutan.

3. Campuran serba beda, seperti campuran beberapa macam gas yang bersentuhan dengan beberapa macam cairan

Percobaan menunjukkan bahwa keadaaan kesetimbangan sistem hidrostatik dapat diberikan dapat diberikan dengan tiga pertolongan koordinat yaitu tekanan, yang ditimbulkan oleh sistem pada lingkungan, volume dan temperatur (Zemansky, et all. 1986).

\section{Hukum Boyle}

Gas di dalam suatu ruang akan mengisi sepenuhnya ruang tersebut, sehingga volume ruang itu sama dengan volume gas. Hubungan tersebut dinyatakan dengan Hukum Boyle "Jika suhu gas yang berada dalam bejana tertutup (tidak bocor) dijaga konstan, maka tekanan gas berbanding terbalik dengan volumenya" . Secara matematis pernyataan tersebut dapat ditulis :

$$
\begin{array}{cr} 
& P V=\text { konstan atau } \\
\text { Dengan : } & P_{1} V_{1}=P_{2} V_{2} \ldots \ldots \ldots \ldots \ldots \ldots \\
& \mathrm{P}=\text { Tekanan }(\mathrm{Pa}) \\
\mathrm{V}=\text { Volume }\left(\mathrm{m}^{3}\right)
\end{array}
$$

\section{Hukum Charles dan Gay-Lussac}

Dalam hukum Charles dan GayLussac dijelaskan tentang hubungan antara suhu dengan volume pada tekanan tetap yang berbunyi : "Jika tekanan gas yang berada dalam bejana tertutup (tidak bocor) dijaga konstan, maka volume gas sebanding dengan suhu mutlaknya". Secara matematis dapat ditulis :

$$
\frac{V}{T}=\text { konstan atau } \frac{V_{1}}{T_{1}}=\frac{V_{2}}{T_{2}} \ldots \ldots
$$

Dengan V adalah volume $\left(\mathrm{m}^{3}\right)$ dan $\mathrm{T}$ adalah suhu mutlak ( $\mathrm{K}$ ). Hubungan antara suhu dan dengan tekanan pada volume tetap juga dijelaskan oleh hukum Charles dan GayLussac yang berbunyi "Jika volume gas yang berada dalam bejana tertutup (tidak bocor) dijaga konstan, maka tekanan gas sebanding dengan suhu mutlaknya". Secara matematis dapat dituliskan

$$
\frac{P}{T}=\text { konstan atau } \frac{P_{1}}{T_{1}}=\frac{P_{2}}{T_{2}} \ldots \ldots \ldots
$$

\section{Mesin Pendingin}

Didalam pengembun zat pendingin berada pada tekanan tinggi dan pada temperatur terendah yang bisa dicapai dengan memakai pendingin udara atau air. Daur pendingin ideal yang diperlihatkan pada diagram P-V pada gambar 1 didapatkan dengan mengabaikan kesukaan yang biasa timbul karena ada golakan, gesekan, kehilangan kalor dan lain sebagainya. Dalam diagram P-V , satu pada $\theta_{H}$, temperatur pengembun dan yang lainnya pada $\theta_{C}$, temperatur penguap.

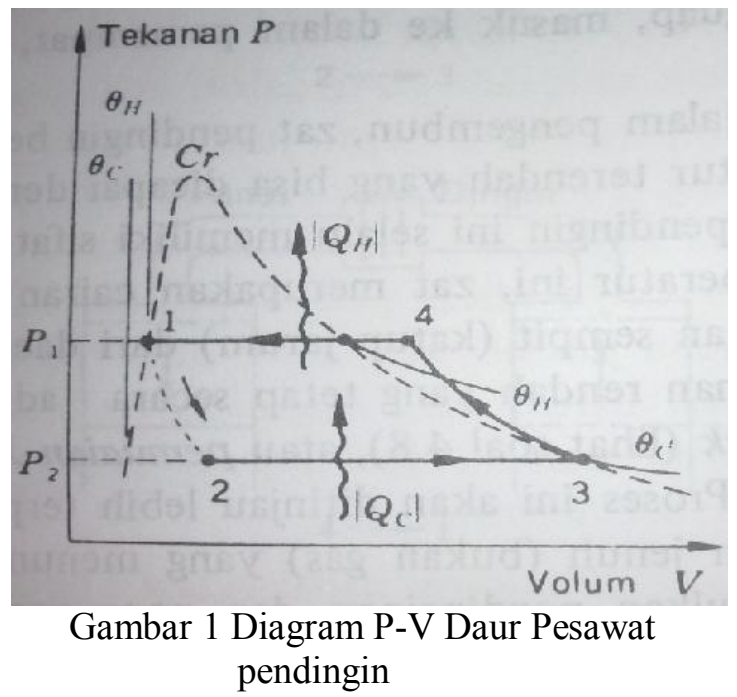

Dimulai dari titik 1 yang menunjukkan keadaan cairan jenuh pada temperature dan tekanan pengembun yang terdiri atas proses berikut ini : 
1. (1-2) yaitu proses yang menyangkut penurunan tekanan dan temperatur. Keadaan antara keadaaan awal dan akhir suatu fluida selama proses ini tidak dapat diberikan dengan pertolongan koordinat termodinamika yang mengacu pada sistem keseluruhan.

2. (2-3) yaitu penguapan isotherm, isobaric yang dalam proses ini kaor $Q_{C}$ diserap oleh zat pendingin pada temperature rendah $Q_{C}$ sehingga mendinginkan bahan dari tendon dingin.

3. (3-4) yaitu pemampatan uap secara adiabat ke temperatur lebih tinggi daripada temperatur pengembunan $\theta_{H}$

4. (4-5) yaitu pendinginan secara isobar dan pengembunan pada $\theta_{H}$

Tujuan setiap pesawat pendingin adalah mengambil sebanyak mungkin kalor dari tendon dingin dengan melakukan kerja sekecil mungkin. Dapat dikatakan keluarannya adalah kalor yang diambil dari tendon dingin dan masukkannya adalah kerja (Zemansky, et all. 1986).

\section{Kondensor}

Fungsi kondensor pada sistem pendinginan kompresi uap adalah untuk mengembunkan uap refrigeran bertekanan tinggi (superheated vapor) Trott, 1989).

Uap yang bertekanan dan bertemperatur tinggi pada akhir kompresi dapat dengan mudah dicairkan dengan cara mendinginkannya dengan medium pendingin. Medium pendingin yang umumnya digunakan adalah air dan udara. Panas dari refrigeran akan meningkatkan suhu medium pendingin yang sesuai dengan persamaan (Dossat, 1961)

\section{Fuzzy Logic Matlab Toolbox}

Salah satu bidang yang ada pada matlab dalam bidang pemodelan adalah fuzzy logic matlab toolbox. Fuzzy logic toolbox adalah fasilitas yang tersedia dalam program matlab untuk membangun sistem fuzzy logic. Fuzzy logic toolbox memberikan fasilitas Graphical User Interface (GUI) untuk mempermudah dalam membangun suatu sistem fuzzy. Pada gambar 2.1 menunjukkan tampilan windows untuk tiap-tiap GUI yang ada dalam fuzzy logic (Mamdani, 1977).

Logika fuzzy merupakan sebuah logika yang memiliki niali kebenaran atau kesamaran (fuzzynes) antara benar dan salah.
Dalam teori logika fuzzy sebuah niali bisa bernilai benar dan salah secara bersamaan namun berapa besar kebenaran dan kesalahan suatu nilai bergantung kepada bobot keanggotaan yang dimilikinya (Rianto, dkk. 2012).

\section{METODE PENELITIAN \\ Waktu dan tempat}

Penelitian ini dilaksanakan di Laboratorium Instrumentasi Jurusan Fisika Fakultas MIPA UNSRAT. Penelitian ini berlangsung dari bulan Juni 2014 sampai November 2014
Alat
1. Komputer
2. Software Fuzzy Logic Matlab Toolbox

\section{Data Penelitian}

Penelitian ini menggunakan data sekunder suhu, laju aliran, dan tekanan pada kondensor sejak 1 Oktober 2012 - 31 Oktober 2012 yang diperoleh dari data PLTP Lahendong.

\section{Prosedur Kerja}

1. Langkah pertama dalam melakukan penelitian menggunakan logika fuzzy adalah membuat fuzzy interface system (FIS). FIS yang dipakai dalam penelitian ini adalah FIS mamdani. FIS mamdani dipakai karena yang paling mudah dimengerti dan paling sesuai dengan naluri manusia. Dalam FIS editor, masukan dibagi dalam 3 variable yaitu tekanan, suhu dan laju aliran sedangkan sebagai keluarannya yaitu volume total pada kondensor.

2. Langkah selanjutnya adalah menentukan fungsi keanggotaan variable, dimana fungsi variable keanggotaan masukan (tekanan, suhu, dan laju aliran uap) dan keluaran (volume total pada kondensor) dibagi menjadi sangat rendah, rendah, sedang, tinggi dan sangat tinggi.

3. Setelah menentukan fungsi keanggotaan, langkah selanjutnya adalah membuat dan menyusun aturan logika fuzzy. Aturan fuzzy yang ditentukan dibuat berdasarkan karakter dari masukan dan keluaran. Aturan-aturan fuzzy ini dibuat dengan menggunakan rule editor. 
4. Setalah menyusun aturan fuzzy, selanjutnya memasukkan variable masukan kedalam proses defuzzyfikasi pada rule viewer. Proses defuzzyfikasi terjadi ketika semua aturan telah selesai dilakukan. Pada rule viewer ini kita bisa menguji hasil dari aturan-aturan yang telah dibuat untuk pemodelan dengan cara memasukkan nilai-nilai variable masukan. Setelah semua langkah diatas telah selesai dilakukan, maka pemodelan suhu, laju aliran dan tekanan menggunakan logika fuzzy dapat dilakukan dengan memvariasikan nilainilai masukan.

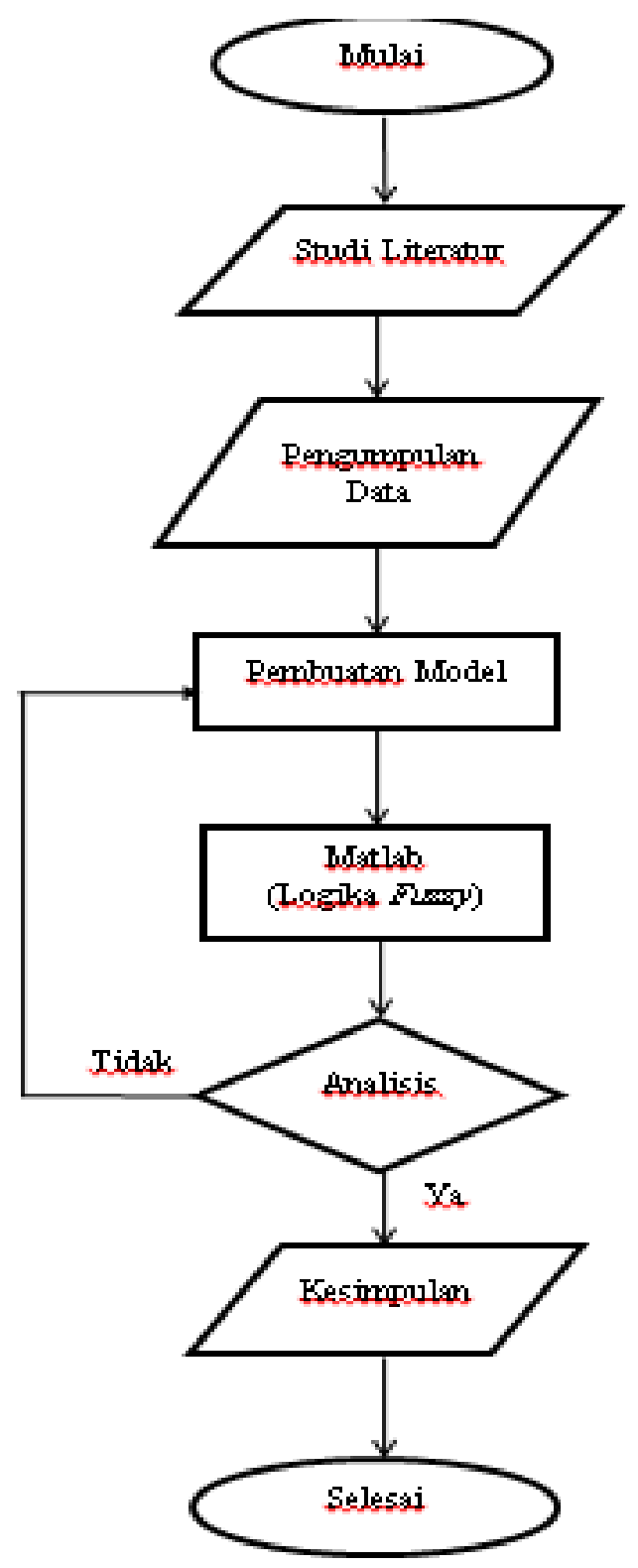

HASIL DAN PEMBAHASAN

Pembuatan Fuzzy Interface System (FIS)

Data yang digunakan dalam penelitian, data pada PLTP Lahendong, yaitu suhu pada kondensor, tekanan pada kondensor dan lau aliran uap yang masuk pada kondensor setelah memutar turbin. Dalam menganalisis data yang ada pada PLTP Lahendong digunakan kontrol logika fuzzy. Dalam memulai bagian analisis maka harus membangun suatu sistem penalaran untuk mengedit dan mengobservasi data. Hal yang dilakukan terlebih dahulu untuk membangun sistem penalaran adalah membuat fuzzy interface system (FIS).

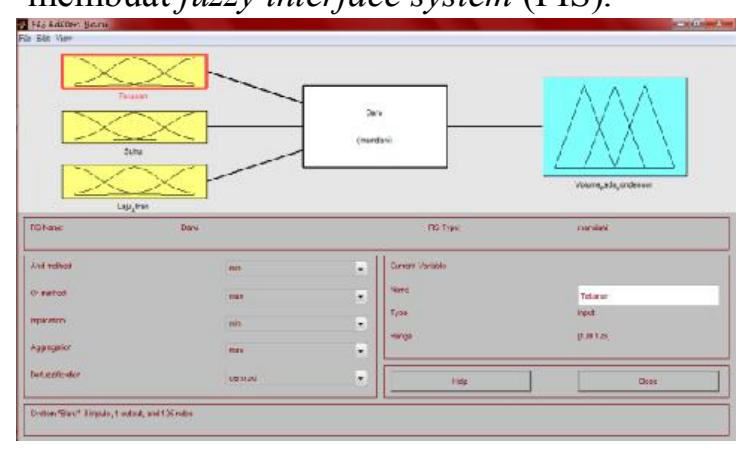

Gambar 2 Fuzzy Interface System

Berikut adalah variabel-variabel masukan yang terdiri dari tekanan, suhu, dan laju aliran uap air serta variabel keluaran ialah volume air pada kondensor. Dalam melakukan masukan harus membuat rangerange pada sistem penalaran fuzzy. Range masukanannya yaitu dari nilai paling masksimum sampai nilai paling minimum berdasarkan data yang didapatkan pada PLTP Lahendong.

Untuk tekanan pada kondensor, range paling minimum dan maksimum setelah dilakukan rekapitulasi data adalah 100 mbar -126 mbar. Pada suhu kondensor adalah 37 derajat - 46 derajat. Pada laju aliran adalah $57 \mathrm{~kg} / \mathrm{s}$ - $93 \mathrm{~kg} / \mathrm{s}$. sedangkan untuk keluarannya (volume laju aliran air pada kondensor) adalah $1761 \mathrm{~kg} / \mathrm{s}-1795 \mathrm{~kg} / \mathrm{s}$.

\section{Pengaturan Membership Function Editor}

Untuk volume air pada kondensor batas maksimum adalah $1808 \mathrm{Kg} / \mathrm{s}$. Range data tersebut dipakai untuk menentukan atau mendefinisikan variable masukan dan keluaran. Hal tersebut diatur dalam membership function editor. Berikut adalah gambar pada bagian membership function editor 
Untuk masukan Tekanan pada kondensor, suhu pada kondensor dan Laju aliran uap dibagi kedalam lima variable yaitu sangat rendah, rendah, sedang, tinggi dan sangat tinggi. Pada variable keluaran juga dibagi dalam lima variable yang sama dengan masukanan. Untuk tipe kurvanya, dipilih kurva trimf. Pada gambar 3 kurva garis berwarna merah menunjukkan pengaturan yang sementara dilakukan untuk suatu range pada masukan.

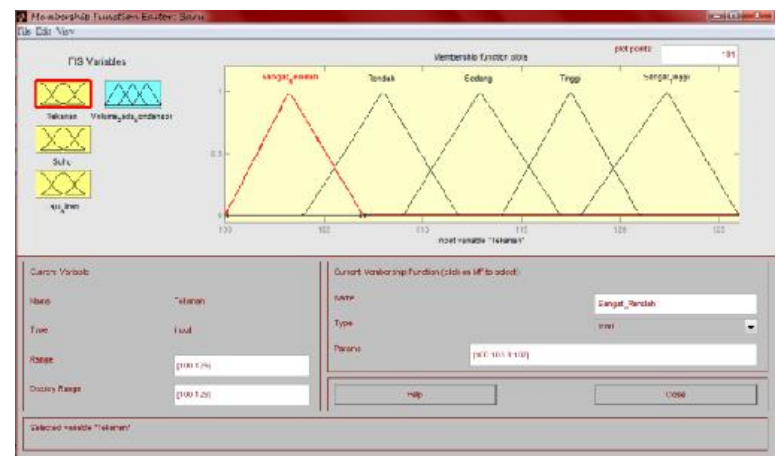

Gambar 3 Membership Function Editor

Selanjutnya setelah menentukan variable masukan dan keluaran dilanjutkan pada penentuan aturan yang sesuai dengan kinerja pada sistem fuzzy.

Berikut adalah gambar rule yang dipakai. Rule yang dipakai dalam penelitian ini adalah 125 rule penalaran untuk aturan fuzzy.

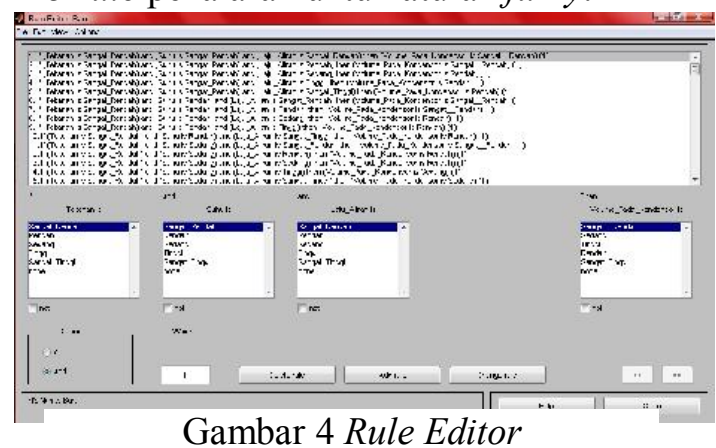

\section{Pengamatan Dan Analisis Pada Rule} Viewer

Setelah melakukan rule editor langkah selanjutnya memasukan data kedalam rule viewer untuk melihat hasil dari proses inferensi.

Pada gambar 5 yang telah disajikan, garis merah yang terdapat dalam rule yang ada menunjukkan batas-batas pada proses inferensi yang telah dilakukan. Warna kuning pada rule tekanan, suhu dan laju aliran menunjukkan letak dimana kondisi suatu masukan yang telah dilakukan. Sedangkan pada volume kondensor warna biru pada rule menunjukkan keadaan volume berdasarkan masukan yang telah dilakukan. Hasil keluaran pada kondensor bergantung pada tekanan, suhu dan laju aliran yang pada kondensor pada selang waktu yang bersamaan.

Proses-proses masukan dan keluaran yang terjadi didalam kondensor dapat terlihat dari rule yang telah dilakukan diatas. Besarnya suatu volume laju aliran pada kondensor bergantung pada masukan yang telah dilakukan. Dari hasil yang telah dilakukan, terlihat bahwa volume air pada kondensor secara umum berada pada volume yang stabil atau sedang. Hal ini terlihat dari data yang berada pada volume laju aliran uap air kondensor yaitu $1.776-1780 \mathrm{~kg} / \mathrm{s}$.

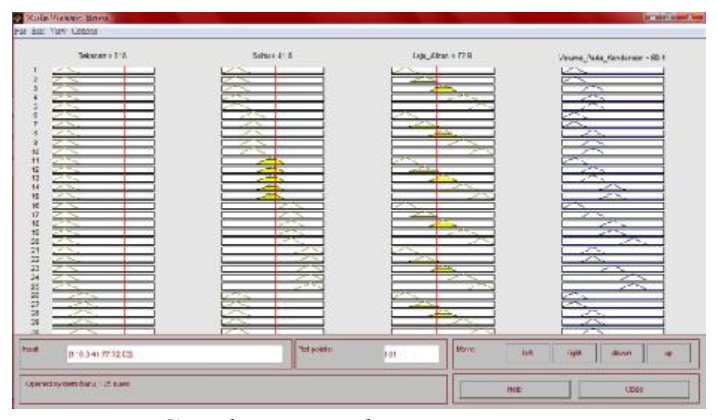

Gambar 5 Rule Viewer

\section{Hubungan Tekanan, Suhu, Laju Aliran Uap dan Volume Air Pada Kondensor}

Volume air pada kondensor sangat dipengaruhi oleh variable-variabel suhu, tekanan dan laju aliran uap yang ada pada kondensor. Oleh karena volume kondensor yang tidak berubah atau statis, berdasarkan hukum Charles dan Gay-Lussac (pers 2.5) maka dapat terlihat bahwa tekanan dan suhu pada kondensor akan berbanding lurus. Jika suhu pada kondensor meningkat maka akan menaikkan tekanan yang ada pada kondensor

Hubungan yang terjadi antara suhu dan tekanan mempengaruhi sistem yang ada pada kondensor. Tekanan yang ada pada kondensor PLTP Lahendong unit 1 harus berada pada keadaan yang vakum, agar lebih kecil dibandingkan dengan tekanan yang ada pada turbin. Kondensor perlu mempertahankan tekanan, suhu, dan laju aliran uap serta volume laju aliran air pada kondensor dapat bekerja maksimal. Pada data yang diambil dari PLTP Lahendong, terlihat bahwa masukan tekanan, suhu dan laju aliran 
uap selalu bervariasi setiap saat, maka volume air pada kondensor juga akan berada pada level yang tidak selalu stabil. Untuk itu masukan dan keluaran kondensor perlu dikontrol agar kondensor dapat bekerja dengan baik

Untuk tekanan rata-rata pada kondensor menurut data PLTP Lahendong unit 1 adalah 110.5 mbar absolut dengan cooling water inlet $\left(1719 \mathrm{Kg} / \mathrm{s}, 29^{\circ} \mathrm{C}\right)$ dan cooling water outlet $\left(1808 \mathrm{Kg} / \mathrm{s}, 41.5^{\circ} \mathrm{C}\right)$. Kondensor harus memiliki tekanan, suhu, dan laju aliran yang tetap dikontrol kestabilannya untuk memperoleh proses kerja yang baik. Suhu yang meningkat didalam kondensor akan mempengaruhi tekanan pada kondensor sehingga proses penarikan uap bekas dari turbin tidak akan baik.

Pada saat yang bersamaan jika laju aliran uap bekas turbin berlebih, maka uap bekas yang akan dikondensasi menjadi air akan memenuhi tabung kondensor serta membuat tekanan pada kondensor menjadi tidak stabil dan dapat merusak system yang ada pada system PLTP Lahendong. Oleh karena itu keterkaitan tekanan, suhu, dan laju aliran dibutuhkan pengontrolan yang baik agar system kondensor dapat efektif.

Pemodelan menggunakan logika fuzzy dapat menjadi menjadi salah satu alternatif pengontrolan yang dapat dipakai untuk mengontrol system yang ada pada kondensor. Hal ini dikarenakan hasil yang diperoleh dari gambar 4.5 menunjukkan keterkaitan yang terkontrol dan saling mempengaruhi sehingga bisa memperoleh system kontrol yang efisien.

\section{Perbandingan Antara Hasil Data PLTP Lahendong dan Hasil Logika Fuzzy}

Hasil yang diperoleh dalam penelitian ini dalam perbandingan hasil data dan Logika Fuzzy tidak terlalu signifikan. Hal tersebut terlihat pada hasil yang didapatkan berdasarkan pengamatan software dan data lapangan. Untuk hasil selisih kuadrat terbesar antara hasil lapangan dan software adalah 9,132701585 sedangkan selisih kuadrat yang terkecil adalah Ini 0,000000203 terlihat dari grafik yang ditunjukkan sebagai berikut. Untuk error yang diperoleh dari kedua perbandingan menggunakan RMSE (rood mean square eror).

Hasil dari RMSE sendiri adalah 0.7847. Nilai RMSE ini jika dilihat dari grafik yang telah tersaji, tidak terjadi penyimpangan yang begitu signifikan. Hasil 0.7847 pada RMSE ini sendiri disebabkan karena adanya selisih pada hasil lapangan dengan hasil logika fuzzy. Estimasi error yang terlihat disebabkan oleh kurangnya keakuratan pada parameter-parameter alat pembacaan suhu, tekanan, laju aliran dan volume kondensor pada PLTP Lahendong yang tidak lagi efisien

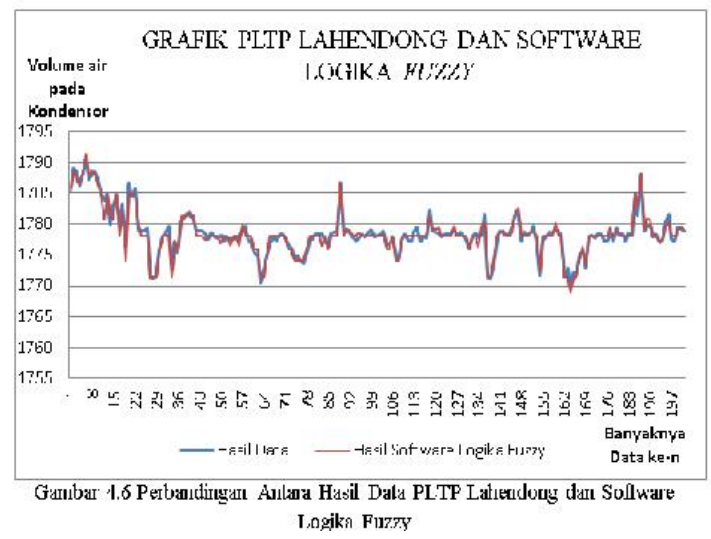

Gambar 6 Perbandingan hasil data PLTP dan Software Logika Fuzzy

\section{KESIMPULAN DAN SARAN Kesimpulan}

Penelitian ini telah membuat model kontrol suhu, tekanan, dan laju aliran uap pada kondensor dengan menggunkan kontrol logika fuzzy, serta memiliki kemampuan pengontrolan mendekati stabil yang ditunjukkan dengan nilai root mean square error (RMSE) sebesar 0,7847

\section{Saran}

1. Pengembangan dalam kontrol logika fuzzy, terlebih dalam membership function dapat lebih lagi dimaksimalkan.

2. Pengembangan dengan menggunakan metode sugeno dalam logika fuzzy

3. Logika fuzzy dapat digunakan sebagai sistem kontrol otomatis dalam sistem lain seperti cooling tower dan demister pada PLTP Lahendong

\section{DAFTAR PUSTAKA}

David, S. William. 1991. Sistem Pengolahan Informasi edisi Kedua. Erlangga, Bandung. 
Dossat, Roy J. 1961. Principles of Refrigeration. John Wiley \& Sons. Jepang

Halliday, Resnick, Walker. 1994 . Dasar dasar Fisika Versi Diperluas, Jilid I. Binarupa Aksara Publisher. Jakarta.

Mamdani, E.H., "Applications of fuzzy logic to approximate reasoning using linguistic synthesis," IEEE Transactions on

Mark W. Zemansky, Richard H. Dittman. 1986. Kalor dan Termodinamika. Penerbit ITB. Bandung

Mamdani, E.H., "Applications of fuzzy logic to approximate reasoning using linguistic synthesis," IEEE Transactions on

Rianto Samosir, Iryanto, Rosman Siregar. 2013. Perbandingan Produksi Kopi Optimum Antara Metode FuzzyMamdani dengan Fuzzy-Sugeno pada PT XYZ. Vol 1, No. 6 (2013), pp. $517-$ 527. Bandung

Trott, AR. 1989. Refrigeration and Air Conditioning. Butterworths.

Cambridge, UK 